\title{
A Novel Three Phase to Seven Phase Conversion Technique Using Transformer Winding Connections
}

\author{
M. Tabrez \\ Electrical Engineering Dept. \\ Indian Institute of Technology \\ Dhanbad, India \\ mdtabrez2008@gmail.com
}

\author{
P. K. Sadhu \\ Electrical Engineering Dept. \\ Indian Institute of Technology \\ Dhanbad, India \\ pradip_sadhu@yahoo.co.in
}

\author{
A. Iqbal \\ Electrical Engineering Dept. \\ Qatar University \\ Doha, Qatar \\ atif.iqbal@qu.edu.qa
}

\begin{abstract}
This paper proposes a novel multiphase transformer connection scheme which converts three phase balanced AC input to seven phase balanced $\mathrm{AC}$ output. Generalized theory to convert a three phase utility supply into any number of phases is presented. Based on the proposed generalized principle, a three phase to seven phase power converting transformer design is presented with connection scheme, analysis and simulation and experimental results of the proposed three phase to seven phase conversion transformer. The proposed transformer in this paper is analyzed and compared with the connection scheme for seven phase available in the literature. The connection scheme is found to have higher power density, lower core area and lower core requirement as compared to the available connection scheme of the same rating. Impedance mismatching between different phases of the transformer is observed in the three phase to seven phase transformer available in the literature. As this mismatching introduces error in study of per phase equivalent circuit diagrams as well as imbalance in voltage and currents. The present design also addresses the impedance mismatching issue and reduces mismatching in the proposed transformer design. A prototype of the proposed system is developed and waveforms are presented. The proposed design is verified using simulation and validated using experimental approach.
\end{abstract}

Keywords-multiphase; seven-phase; transformer connections; high phase order

\section{INTRODUCTION}

Multiphase systems are known for reliability, fault tolerance and high power carrying capabilities [1]. There are papers about this application reagarding power generation [2, $3]$, transmission [4, 5] and utilization [6, 7]. The numerous advantages offered by multiphase systems have attracted researchers' interest that include higher machine torque density, reduced torque ripples, reduced harmonic currents, better transient and steady-state performance, and more robust control of multiphase based drives. Multi-phase AC power is generated from three phase power by two methods. One is by converting three phase $\mathrm{AC}$ to a DC power and then converting it back to multiphase AC (i.e. AC-DC-AC). The other one is through multiphase power converting transformers. The second method utilizes transformer winding in a special connection and turns ratios while the first method needs rectifiers and inverters. Multiphase is found to produce less ripple with a higher frequency of ripple in an AC-DC rectifier system. Thus, 6- and 12-phase transformers are designed to feed a multi-pulse rectifier system. Recently, 24-phase and 36-phase transformer systems have been proposed for supplying a multi-pulse rectifier system [8-11]. The reason of 6-, 12-, or 24-phase system is that these numbers are multiples of three and designing this type of system is simple and straight forward. As far as odd numbers of phases are concerned, limited literature sources are found. Prototypes designed and tested for a three to five phase and three to seven phase power converting transformer are reported in [12-14]. One of which is a Scott based three to five phase converting power transformer design [14]. The approach of [14] is extended in this paper for three phase to seven phase transformer. The block diagram of the proposed system is shown in Figure 1. The fixed conventional voltage and fixed frequency available three phase AC supply can be transformed into a fixed voltage and fixed frequency seven-phase AC supply. The output, however, may be made variable by inserting the autotransformer either at input or output side. Depending on the requirement the input and output can be arranged in the following manner:

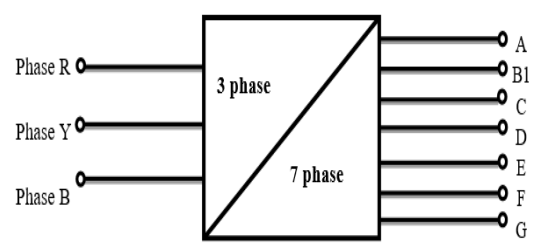

Fig. 1. Block diagram of the proposed system

1) Input Scott, output star

2) Input Scott, output polygon

The primary windings are connected in Scott connection to produce a balanced two phase flux in the core of the transformer while secondary side connection is discussed in the following sections III, A " $R$ ", " $Y$ " and " $B$ " represents three phases of input power while A, B1, C,....G, represents seven phase output voltages with respect to star point. In section II, phasor approach is presented to explain principle of phase 
conversion of a general three to $n$ phase and derived turns ratios and connection scheme for three to seven phase power conversion from the same theory as given in section I. Winding arrangements are presented in section III. Simulation and experimental results, comparison, scope of research and conclusions are presented in sections IV, $\mathrm{V}$ and VI, respectively.

\section{METHOD AND PRINCIPLES OF PHASE CONVERSION}

A general theory of phase transformation using transformers to convert from $\mathrm{m}$ to $\mathrm{n}$ number of phases on a $\mathrm{k}$ limbed transformer is presented in [15-17]. In this paper the theory of phase transformation is presented by graphical approach using vectors and phasor diagrams of different phases. This approach findings are same the same with that of [15]. It is well known that any odd number of phases $m$ can be converted to $(m-1) / 2$ decoupled $(\alpha, \beta)$ planes and one zero sequence, so for three phase balanced phase one can convert it to one decoupled $(\alpha, \beta)$ plane or in other words, in balanced two phase ac supply. Scott connection is the method to implement it. Figure 2 shows the phasor diagrams of input and output of the proposed transformer. Figure 2(a) is the phasor diagram of the input phase based on Scott connection. Referring to Figure 2, assume the number of turns in the two cores of primary be $\mathrm{N}_{1}$ and $\mathrm{N}_{2}$ in winding RO and YB. And RMS voltage of each phase be V. Since Volts per turn is the same for all three windings (RO, YO and $\mathrm{BO}$ ) hence,

$$
\frac{V_{R O}}{N_{1}}=\frac{V_{Y O}}{\left(\frac{N_{2}}{2}\right)}=\frac{V_{B O}}{\left(\frac{N_{2}}{2}\right)}
$$

Applying geometrical relation to the phasor diagram of Figure 2(a), resulting to:

$$
\begin{aligned}
& \frac{\sqrt{3} V}{N_{1}}=\frac{V}{\left(\frac{N_{2}}{2}\right)}=\frac{V}{\left(\frac{N_{2}}{2}\right)} \\
& \frac{1}{2} N_{2}=\frac{1}{\sqrt{3}} N_{1}
\end{aligned}
$$

Since winding YB is divided into two parts. Hence from (1) and (2), the no of turns for each phase of the input would be in ratios of $1: 1 / \sqrt{3}: 1 / \sqrt{3}$ as tabulated in Table $\mathrm{I}$.

TABLE I. TURNS RATIOS OF PRIMARY WINDINGS

\begin{tabular}{|c|c|}
\hline Windings & Ratio (\% of primary) \\
\hline $\mathrm{RO}$ & $100 \%$ \\
\hline $\mathrm{YO}$ & $57.78 \%$ \\
\hline $\mathrm{BO}$ & $57.78 \%$ \\
\hline
\end{tabular}

Referring to Figure 3, assume voltage $V_{\alpha}$ and $V_{\beta}$ be the outcome of three phase to two phase conversion with a primary Scott connection. $V_{\alpha}$ and $V_{\beta}$ are voltage induced in winding "RO" and "YB" and have equal RMS value as that of supply phase but they are 90 degrees phase apart. The number of turns in winding $\mathrm{a}_{1} \mathrm{a}_{2}$ is kept equal to "RO" so voltage induced $V a$ in winding $a_{1} a_{2}$ is the reference voltage and number of turns will be reference for other windings. In terms of magnitude $V_{l}=V_{a}=V_{\alpha}$. Also from phasor $V_{\beta}=j V_{\alpha}$.

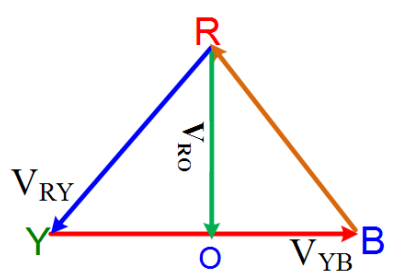

(a)

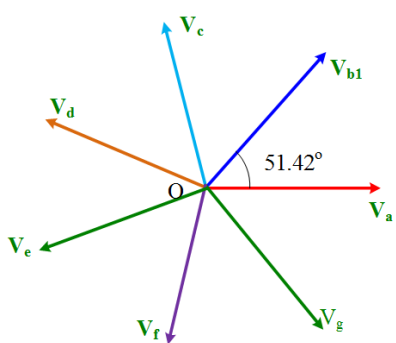

(b)
Fig. 2. Phasor diagram of (a) input voltage and (b) output voltage of the designed transformer

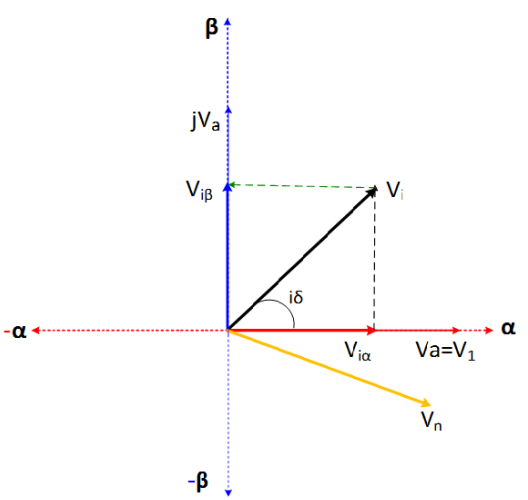

Fig. 3. Phasor diagram of a two phase to $n$ phase conversion

Let's assume a phase conversion of two phase to $n$-number of phases (Figure 3). Let $V_{i}$ be the $i^{\text {th }}$ phasor of an $n$ phases system at an angle $i \delta$ and have magnitude $V$, and $\delta=2 \pi / \mathrm{n}$. Its projection along axis $\alpha$ and $\beta$ would be $V_{i \alpha}$ and $V_{i \beta}$ for $i^{\text {th }}$ phase. For phasor of $i^{t h}$ phase

$$
\begin{aligned}
& V_{i \alpha}=V_{i} \cos (i \delta) \\
& \frac{V_{i \alpha}}{V_{i}}=\cos (i \delta) \\
& a_{\alpha}=\cos (i \delta)
\end{aligned}
$$

Similarly,

$$
\begin{aligned}
& V_{i \beta}=V_{i} \sin (i \delta) \\
& \frac{V_{i \beta}}{V_{i}}=\sin (i \delta) \\
& a_{\beta}=\sin (i \delta)
\end{aligned}
$$

where:

$\mathrm{i}=0,1,2 \ldots \ldots \ldots(\mathrm{n}-1), \mathrm{V}_{\mathrm{i} \alpha}$, -Projection of $\mathrm{i}^{\text {th }}$ phasor along $\mathrm{x}$-axis, $\mathrm{V}_{\mathrm{i} \beta}$-Projection of $\mathrm{i}^{\text {th }}$ phasor along $\mathrm{y}$-axis, $\mathrm{a}_{\alpha}$-Turns ratio for $\mathrm{i}^{\text {th }}$ phase along $\mathrm{x}$-axis or with respect to winding on Core 1 , $\mathrm{a}_{\beta}$-Turns ratio for $\mathrm{i}^{\text {th }}$ phase along $\mathrm{y}$-axis or with respect to winding wound on Core 2 which produces a flux 90 degrees out of phase with respect to core 1 .

Hence an $n$ phase transformation from a two phase balanced supply could be achieved by employing two core 
transformer with a pulsating flux of 90 degrees out of phase. For $n$-number of phases, one can get turns ratios of individual windings by varying $i$ from 0 to $n-1$ and putting $\delta=2 \pi / \mathrm{n}$. Hence voltage equation and turns ratios can be written in matrix as shown in equations (5) and (6). In matrix form the voltage relationship can be generalized as:

$$
\left[\begin{array}{l}
V_{1} \\
V_{2} \\
\cdot \\
\cdot \\
V_{i} \\
\cdot \\
V_{n}
\end{array}\right]=\left[\begin{array}{ll}
1 & 0 \\
\cos (\delta) & \sin (\delta) \\
\cdot & \cdot \\
\cos (i-1) \delta & \sin (i-1) \delta \\
\cdot & \cdot \\
\cos (n-1) \delta & \sin (n-1) \delta
\end{array}\right]\left[\begin{array}{l}
V_{\alpha} \\
V_{\beta}
\end{array}\right]
$$

whereas turns ratios can be generalized as

$$
\left[\begin{array}{ll}
1 & 0 \\
\cos (\delta) & \sin (\delta) \\
\cdot & \cdot \\
\cdot & \cdot \\
\cos (i-1) \delta & \sin (i-1) \delta \\
\cdot \cos (n-1) \delta & \cdot \sin (n-1) \delta
\end{array}\right]
$$

\section{A. Three Phase to Seven Phase Conversion}

The matrix in (5) converts to matrix in (7) for a seven phase output. Turns ratios can be tabulated from (7) as shown in Table II. $\mathrm{a}_{\alpha}$ and $\mathrm{a}_{\beta}$ represents the turns ratios of the secondary winding with respect to "RO" and "YB" primary windings respectively.

$$
\left[\begin{array}{l}
V_{a} \\
V_{b} \\
V_{c} \\
V_{d} \\
V_{e} \\
V_{f} \\
V_{g}
\end{array}\right]=\left[\begin{array}{ll}
1 & 0 \\
\cos (\delta) & \sin (\delta) \\
\cos (2 \delta) & \sin (2 \delta) \\
\cos (3 \delta) & \sin (3 \delta) \\
\cos (4 \delta) & \sin (4 \delta) \\
\cos (5 \delta) & \sin (5 \delta) \\
\cos (6 \delta) & \sin (6 \delta)
\end{array}\right]\left[\begin{array}{l}
V_{\alpha} \\
V_{\beta}
\end{array}\right]
$$

Positive sign denotes phase voltage addition and negative sign denotes phase voltage subtraction. Hence the instantaneous voltage of each phase are described in (8). Figure 4 is the graphical and analytical representation that shows how the voltage of each phase in system is made from two phase voltage induced in the windings of each core. Proper selection of polarity and voltage ratio $(0.623,0.7818$ in this case) creates the desired magnitude and phase difference. Though Figure 4 shows the waveform of only one output voltage (Phase B1) with respect to the star point. The other six phase voltages are created in the same manner. Assuming the 7 phasors of the output are balanced as shown in Figure 2(b) and based on star or heptagon connection of secondary windings, one can get one phase voltage and three line voltages namely.

These voltages are defined here as:
- Phase Voltage: Voltages of each phase with respect to neutral/star point "O". $\mathrm{V}_{\mathrm{a}}, \mathrm{V}_{\mathrm{b}}, \mathrm{V}_{\mathrm{c}}, \mathrm{V}_{\mathrm{d}}, \mathrm{V}_{\mathrm{e}}, \mathrm{V}_{\mathrm{f}}, \mathrm{V}_{\mathrm{g}}$.

- Adjacent Line Voltage: Voltage difference of two phases having a phase difference of 51.42degrees, e.g., $\mathrm{V}_{\mathrm{ab} 1}, \mathrm{~V}_{\mathrm{blc}}$, $\mathrm{V}_{\text {cd, }} \mathrm{V}_{\text {de }}, \mathrm{V}_{\text {ef }}, \mathrm{V}_{\text {fg }}, \mathrm{V}_{\text {ga }}$

- Non-adjacent1 Line Voltage: Voltage difference of two phases having a phase difference of $2 \times 51.42$ degrees, e.g., $\mathrm{V}_{\mathrm{ac}}, \mathrm{V}_{\mathrm{bld}}, \mathrm{V}_{\mathrm{ce}}, \mathrm{V}_{\mathrm{df}}, \mathrm{V}_{\mathrm{eg}}, \mathrm{V}_{\mathrm{fa}}, \mathrm{V}_{\mathrm{gb}}$.

- Non-adjacent2 Line Voltage: Voltage difference of two phasors having a phase difference of $3 \times 51.42$ degrees, e.g., $\mathrm{V}_{\mathrm{ad}}, \mathrm{V}_{\mathrm{ble}}, \mathrm{V}_{\mathrm{cf},} \mathrm{V}_{\mathrm{dg}}, \mathrm{V}_{\mathrm{ea}}, \mathrm{V}_{\mathrm{fb} 1}, \mathrm{~V}_{\mathrm{gc}}$

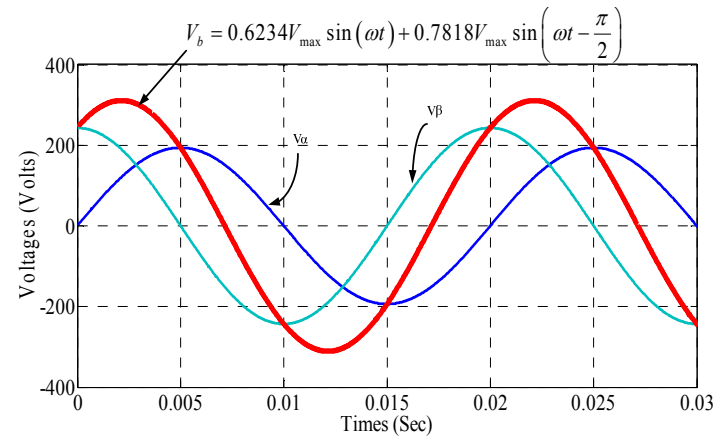

Fig. 4. Waveform of output voltage construction from induced winding voltages.

$$
\begin{aligned}
V_{a} & =V_{\alpha} \operatorname{Sin}(\omega t) \\
V_{b} & =0.6234 V_{\max } \sin (\omega t)+0.7818 V_{\max } \sin \left(\omega t-\frac{\pi}{2}\right) \\
& =V_{\max } \sin \left(\omega t-\frac{2 \pi}{7}\right) \\
V_{c} & =-0.2225 V_{\max } \sin (\omega t)+0.975 V_{\max } \sin \left(\omega t-\frac{\pi}{2}\right) \\
& =V_{\max } \sin \left(\omega t-\frac{4 \pi}{7}\right) \\
V_{d} & =-0.900 V_{\max } \sin (\omega t)+0.4338 V_{\max } \sin \left(\omega t-\frac{\pi}{2}\right) \\
& =V_{\max } \sin \left(\omega t-\frac{6 \pi}{7}\right) \\
V_{e} & =-0.900 V_{\max } \sin (\omega t)-0.4338 V_{\max } \sin \left(\omega t-\frac{\pi}{2}\right) \\
& =V_{\max } \sin \left(\omega t-\frac{8 \pi}{7}\right) \\
V_{f} & =-0.2225 V_{\max } \sin (\omega t)-0.975 V_{\max } \sin \left(\omega t-\frac{\pi}{2}\right) \\
& =V_{\max } \sin \left(\omega t-\frac{10 \pi}{7}\right) \\
V_{g} & =0.6234 V_{\max } \sin (\omega t)-0.7818 V_{\max } \sin \left(\omega t-\frac{\pi}{2}\right) \\
& =V_{\max } \sin \left(\omega t-\frac{12 \pi}{7}\right)
\end{aligned}
$$


TABLE II. TURNS RATIOS OF DIFFERENT WINDINGS

\begin{tabular}{|c|c|c|c|}
\hline A axis & $\mathbf{a}_{\boldsymbol{\alpha}}$ & $\boldsymbol{\beta}$ axis & $\mathbf{a}_{\boldsymbol{\beta}}$ \\
\hline $\mathrm{a}_{1} \mathrm{a}_{2}$ & 1 & & \\
\hline $\mathrm{b}_{1} \mathrm{~b}_{2}$ & +0.6234 & $\mathrm{~b}_{3} \mathrm{~b}_{4}$ & +0.7818 \\
\hline $\mathrm{c}_{1} \mathrm{c}_{2}$ & -0.2225 & $\mathrm{c}_{3} \mathrm{c}_{4}$ & +0.9749 \\
\hline $\mathrm{d}_{1} \mathrm{~d}_{2}$ & -0.9009 & $\mathrm{~d}_{3} \mathrm{~d}_{4}$ & +0.4338 \\
\hline $\mathrm{e}_{1} \mathrm{e}_{2}$ & -0.9009 & $\mathrm{e}_{3} \mathrm{e}_{4}$ & -0.4338 \\
\hline $\mathrm{f}_{1} \mathrm{f}_{2}$ & -0.2225 & $\mathrm{f}_{3} \mathrm{f}_{4}$ & -0.9749 \\
\hline $\mathrm{g}_{1} \mathrm{~g}_{2}$ & +0.6234 & $\mathrm{~g}_{3} \mathrm{~g}_{4}$ & -0.7818 \\
\hline
\end{tabular}

\section{METHODOLOGY}

\section{A. Connection Scheme}

Two separate cores are used where each core contains the primary and secondary coils with the connection and turns ratios shown in Figure 5 and Table III. Primary terminals are connected via Scott connection while the 13 secondary terminals are connected in such a way that the voltages are added or subtracted as in Table IV resulting in a seven phase output. The connection scheme of the secondary windings to obtain an output is illustrated in Figure 3 and the corresponding phasor diagram is illustrated in Figure 2(b). The generation of output phase voltages with requisite phase angles of 51.42 degrees between phases is obtained using appropriate turns ratios, and the governing phasor equations are illustrated in (8). The turns ratios are different in each phase. The choice of turns ratio is the key in creating the required phase displacement in the output phase voltages. The input phases are designated with letters " $\mathrm{R}$ " " $\mathrm{Y}$ ", and " $\mathrm{B}$ " and the output are designated as "A", "B1", "C", "D", "E" "F" and "G" as illustrated in Figure 1. The output phase "A" is along the input phase " $R$ ". The output phase "B1" results from the phasor sum of winding voltage " $b_{1} b_{2}$ " and " $b_{3} b_{4}$ ", the output phase " $C$ " is obtained by the phasor sum of winding voltages " $\mathrm{c}_{1} \mathrm{c}_{2}$ " and " $\mathrm{c}_{3} \mathrm{c}_{4}$ ". The output phase " $\mathrm{D}$ " is obtained by the phasor addition of winding voltages " $\mathrm{d}_{1} \mathrm{~d}_{2}$ " and " $\mathrm{d}_{3} \mathrm{~d}_{4}$ " and the output phase "E" results from the phasor sum of the winding voltages " $\mathrm{e}_{1} \mathrm{e}_{2}$ " and " $\mathrm{e}_{3} \mathrm{e}_{4}$ " and so on.

$$
\begin{aligned}
& V_{A N}=V_{a_{1} a_{2}} \\
& V_{B 1 N}=V_{b_{1} b_{2}}+V_{b_{3} b_{4}} \\
& V_{C N}=-V_{c_{1} c_{2}}+V_{c_{3} c_{4}} \\
& V_{D N}=-V_{d_{1} d_{2}}+V_{d_{3} d_{4}} \\
& V_{E N}=-V_{e_{1} e_{2}}-V_{e_{3} e_{4}} \\
& V_{F N}=-V_{f_{1} f_{2}}-V_{f_{3} f_{4}} \\
& V_{G N}=V_{g_{1} g_{2}}-V_{g_{3} g_{4}}
\end{aligned}
$$

In this way, seven phases are obtained. The transformation from three to seven and vice-versa is further obtained by using the relation given in (8). Figure 5 shows a labeled diagram of proposed transformer.

\section{B. Calculation of Turns Ratios}

Referring to Figure 2(a), let the number of turns in the two cores of the primary be $\mathrm{N}_{1}$ and $\mathrm{N}_{2}$ in winding RO and YB and the RMS voltage be V. Volts per turn is the same on all three windings, hence

$$
\frac{V}{N_{1}}=\frac{(\sqrt{3} / 2)}{N_{2}} V \quad \text { and } \quad \frac{N_{2}}{2}=r N_{1} \quad \text { where } \quad r=\frac{1}{\sqrt{3}}
$$

The number of turns would be in the ratios of $1: r: r$ for the primary winding to produce 2-phase flux. Two separate iron cores are designed, one of them carrying one primary (RO) and seven secondary coils, while second core carrying two primary coils connected at point "O" and of equal turns ratios but of $r \ldots . . r$ times that of winding "RO" and six secondary coils. The 14 secondary terminals are connected either in star or heptagon arrangement. The connection scheme of secondary windings to obtain star output is illustrated in Figure 3 and the corresponding phasor diagram is illustrated in Figure 2(b). The generation of output phase voltages with required phase angles of $360 / 7=51.428$ degrees is shown in Figure 4. Voltage transformation ratio is taken as 1 , as an assumption, because the objective is to obtain seven phase balance output. For the secondary step up or step down voltage, a scaling factor would be multiplied to each number of turns as shown in Tables II and III to get the desired output voltage. The windings arrangements are shown in Figure 5. and Table III.

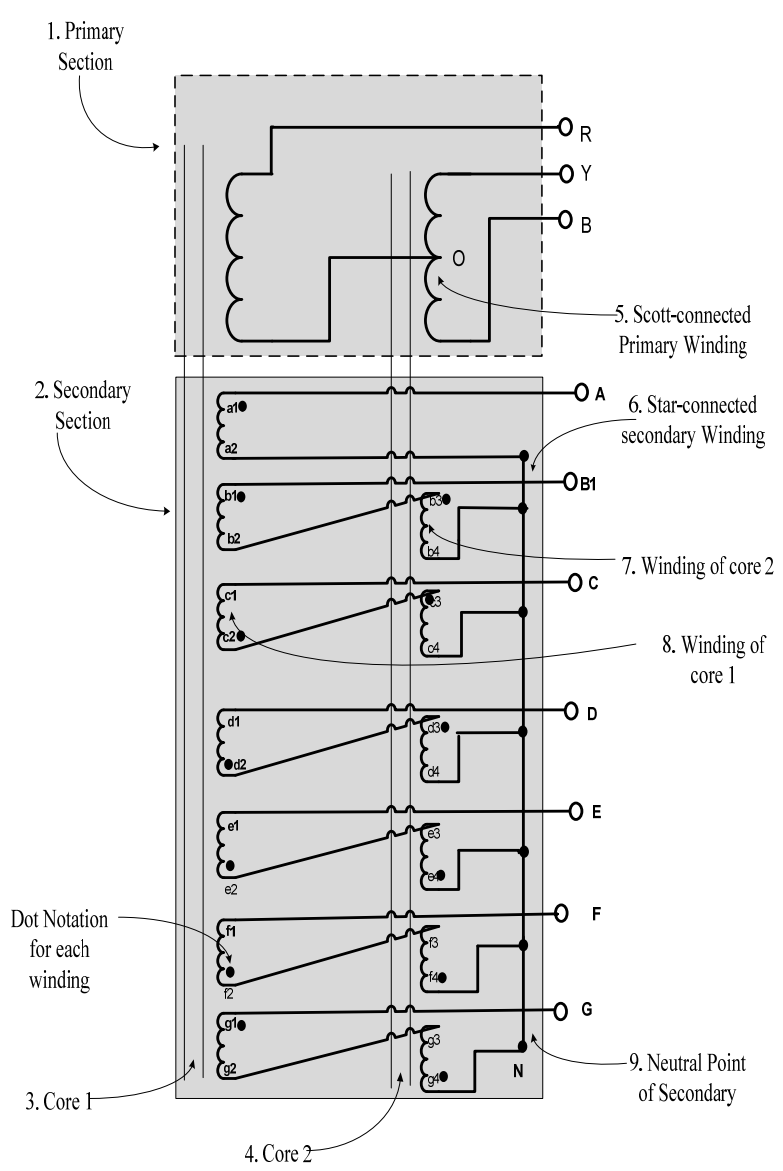

Fig. 5. Winding arrangement of primary and secondary of the transformer 
TABLE III. TURNS RATIOS OF SECONDARY WINDINGS WITH RESPECT TO PRIMARY WINDING RO

\begin{tabular}{|c|c|c|c|c|c|}
\hline$\alpha$ Axis & $\begin{array}{c}\text { Turns } \\
\text { ratio }\end{array}$ & Polarity & BAxis & $\begin{array}{c}\text { Turns } \\
\text { ratio }\end{array}$ & Polarity \\
\hline$a_{1} a_{2}$ & 100 & + & & & \\
\hline$b_{1} b_{2}$ & 62.34 & + & $\mathrm{b}_{3} \mathrm{~b}_{4}$ & 78.18 & + \\
\hline $\mathrm{c}_{1} \mathrm{c}_{2}$ & 22.25 & - & $\mathrm{c}_{3} \mathrm{c}_{4}$ & 97.49 & + \\
\hline $\mathrm{d}_{1} \mathrm{~d}_{2}$ & 90.09 & - & $\mathrm{d}_{3} \mathrm{~d}_{4}$ & 43.38 & + \\
\hline $\mathrm{e}_{1} \mathrm{e}_{2}$ & 90.09 & - & $\mathrm{e}_{3} \mathrm{e}_{4}$ & 43.38 & - \\
\hline $\mathrm{f}_{1} \mathrm{f}_{2}$ & 22.25 & - & $\mathrm{f}_{3} \mathrm{f}_{4}$ & 97.49 & - \\
\hline $\mathrm{g}_{1} \mathrm{~g}_{2}$ & 62.34 & + & $\mathrm{g}_{3} \mathrm{~g}_{4}$ & 78.18 & - \\
\hline
\end{tabular}

The proposed transformer is first simulated through MATLAB/SIMULINK. From which a prototype is developed based on the presented concept. The waveforms of the output voltage are taken into consideration to validate the design with the following results (Figures 7-13).

\section{RESUlts}

\section{A. A. Simulation Results}

Table IV values are taken from Table III. The proposed scheme gives a balanced seven phase output voltage and balanced output current under RL load as shown in Figures 713. The designed transformer is simulated and the inbuilt transformer blocks are used to simulate the conceptual design. The Simulink model diagram is presented in Figure 6. The appropriate turns ratios are set in the dialog box and the simulation is set to run. Turns ratios and polarity of winding connection are those shown in Table III. The output is a balanced seven phase supply for a balanced three-phase input (Figures 7-8) and an unbalanced output is a seen for an unbalanced three-phase input. Three different line voltages can be obtained as shown in section III. The magnitude and phase angle is shown in Table $\mathrm{V}$. The Table $\mathrm{V}$ results are obtained from simulation but they can be verified from phasor diagram and geometrical analysis.

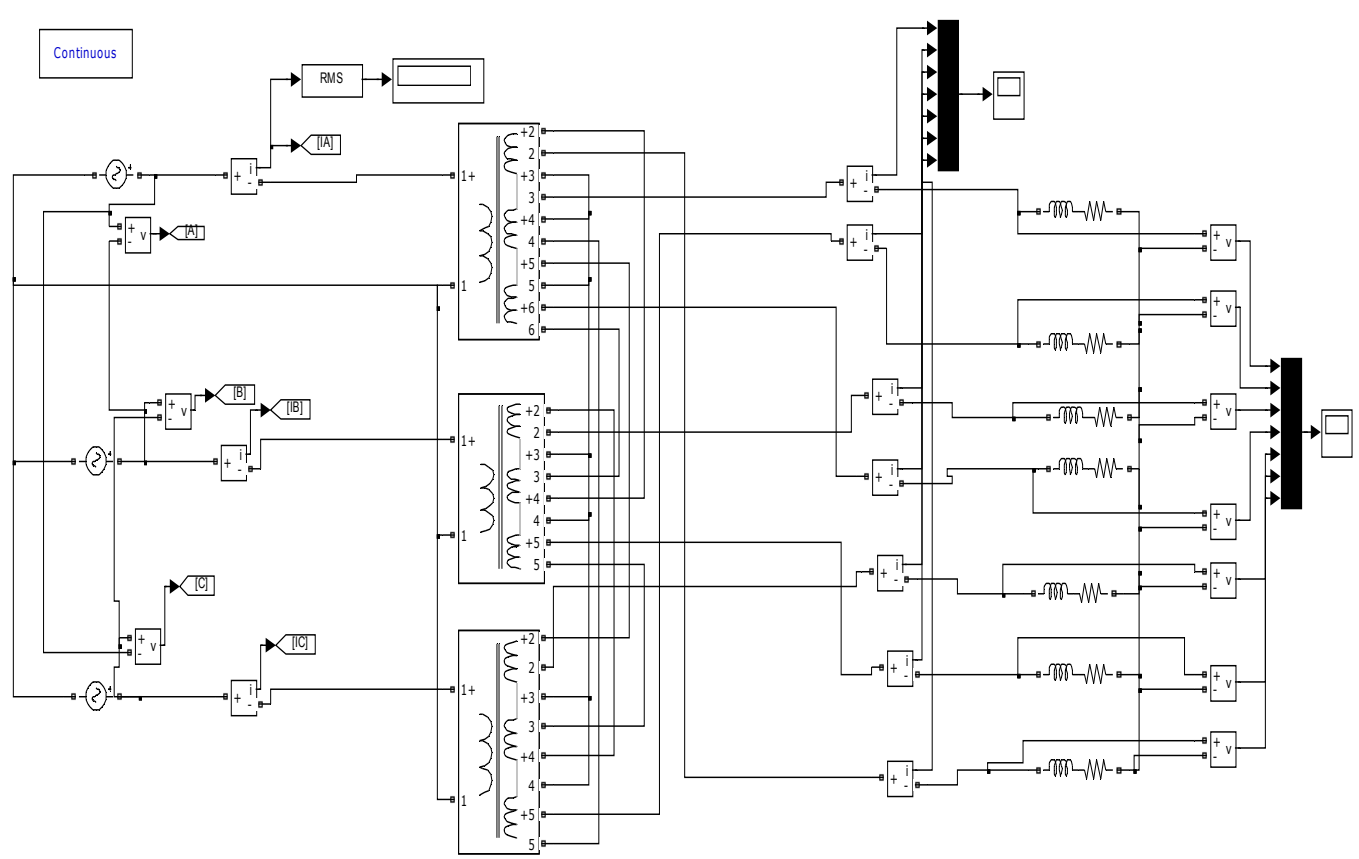

Fig. 6. The SIMULINK model of the proposed system

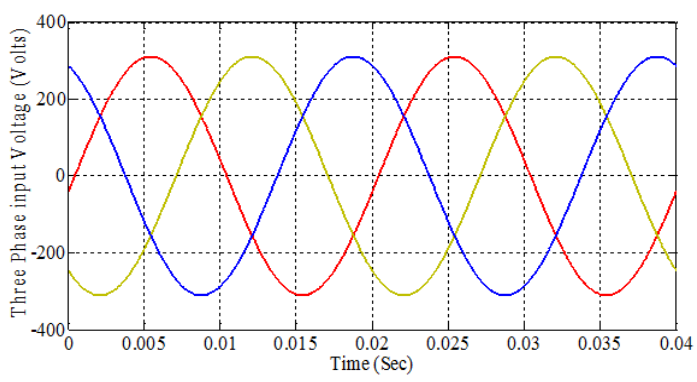

Fig. 7. Three phase balanced input

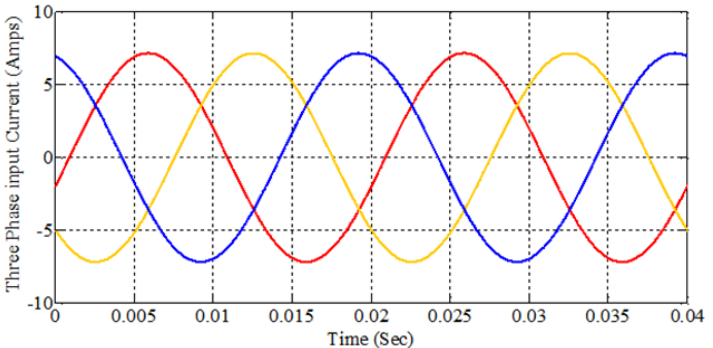

Fig. 8. Three phase balanced input current drawn by the transformer from the source. 
TABLE IV. PARAMETERS FOR SIMULATION

\begin{tabular}{|c|c|c|}
\hline $\begin{array}{l}\text { Connection } \\
\text { Scheme }\end{array}$ & $\begin{array}{l}\text { Primary- Scott } \\
\text { connection }\end{array}$ & Seconday-Heptagon \\
\hline \multirow{4}{*}{$\begin{array}{c}\text { Source and } \\
\text { Load Parameter }\end{array}$} & S & $10 \mathrm{KVA}$ \\
\hline & $\mathrm{V}$ (pri) & $220 \mathrm{~V} / \mathrm{Ph}$ \\
\hline & $\mathrm{V}(\mathrm{sec})$ & $220 \mathrm{~V} / \mathrm{Ph}$ \\
\hline & $\begin{array}{l}\text { Load(7 phase star } \\
\text { connected load) }\end{array}$ & $\mathrm{R}=100 \Omega, \mathrm{L}=48 \mathrm{mH}$ \\
\hline \multirow{11}{*}{$\begin{array}{c}\text { Solver } \\
\text { Parameters }\end{array}$} & Simulation Time & $0-0.004 \mathrm{sec}$ \\
\hline & Solver & Ode45(Dormand-Prince) \\
\hline & Type of Solver & Variable Step \\
\hline & Min/Max step size & Auto \\
\hline & $\begin{array}{l}\text { Zero crossing } \\
\text { control }\end{array}$ & Local Settings \\
\hline & $\begin{array}{l}\text { Zero crossing } \\
\text { algorithm }\end{array}$ & Nonadaptive \\
\hline & $\begin{array}{c}\text { Number of } \\
\text { consecutive min } \\
\text { steps }\end{array}$ & 1 \\
\hline & $\begin{array}{c}\text { Shape } \\
\text { preservation }\end{array}$ & NO \\
\hline & $\begin{array}{l}\text { Absolute } \\
\text { tolerance }\end{array}$ & Auto \\
\hline & Time Tolerance & $10 * 128 *$ eps \\
\hline & $\begin{array}{c}\text { Number of } \\
\text { Consecutive zero } \\
\text { crossings }\end{array}$ & 1000 \\
\hline
\end{tabular}

TABLE V. MAGNITUDE AND PHASE ANGLE OF DIFFERENT LINE VOLTAGE

\begin{tabular}{|c|c|c|c|}
\hline Voltage & RMS Value & Angle & $\begin{array}{c}\text { Ratio with } \\
\text { Phase Voltage }\end{array}$ \\
\hline Phase Voltage & 219.65 & $0.00^{\circ}$ & 1.00 \\
\hline $\begin{array}{c}\text { Adjacent Line } \\
\text { Voltage }\end{array}$ & 190.60 & $-64.26^{\circ}$ & 0.866 \\
\hline $\begin{array}{c}\text { Non-adjacent1 } \\
\text { Line Voltage }\end{array}$ & 343.54 & $-38.63^{\circ}$ & 1.561 \\
\hline $\begin{array}{c}\text { Non-adjacent2 } \\
\text { Line Voltage }\end{array}$ & 428.23 & $-12.89^{\circ}$ & 1.946 \\
\hline
\end{tabular}

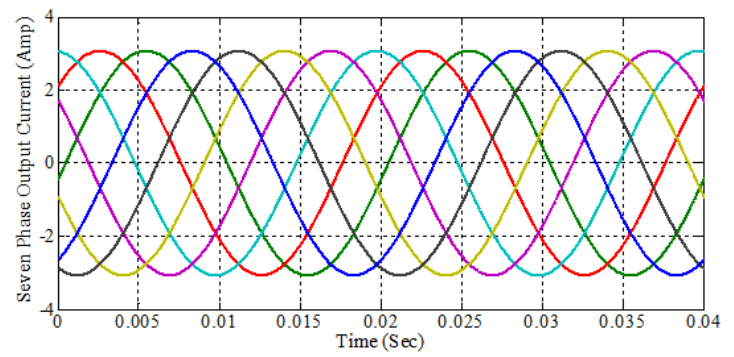

Fig. 9. Seven phase balanced output current

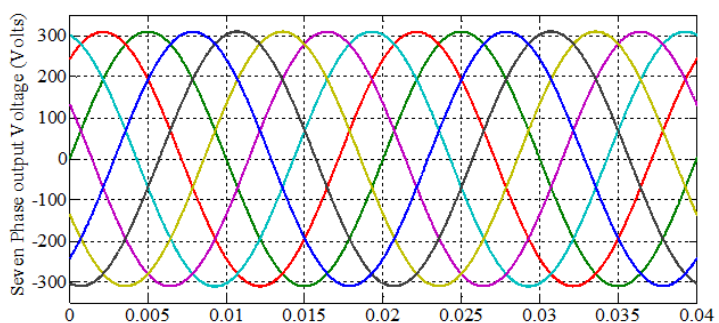

Fig. 10. Seven phase balanced output Phase Voltage

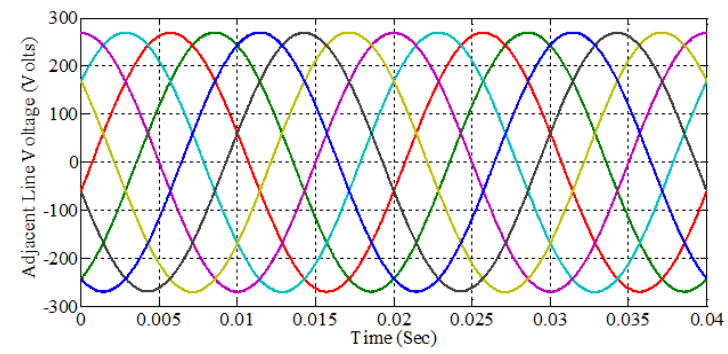

Fig. 11. Seven phase Adjacent Line Voltage

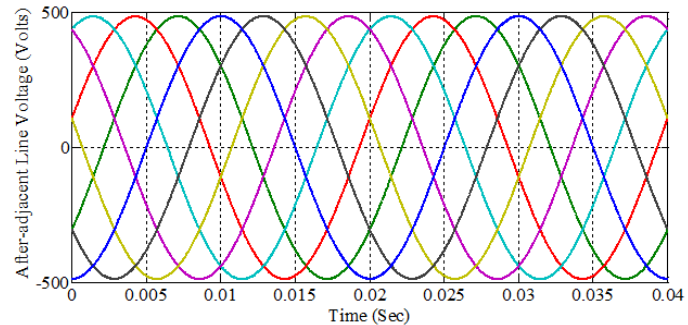

Fig. 12. Seven phase Non-Adjacent1 Line Voltage

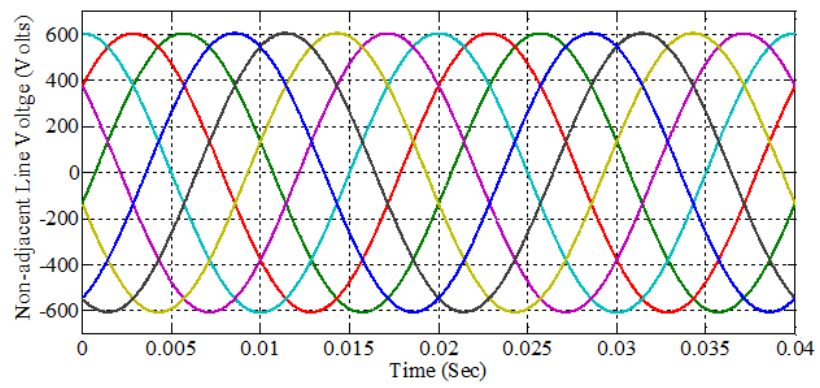

Fig. 13. Seven phase Non-Adjacent2 Line Voltage

\section{B. Experimental Results}

Based on the concept developed in sections II and III and the scheme of section IV, a prototype transformer is developed. The transformer is of $2 \mathrm{kV} \mathrm{A}, 220 \mathrm{~V} /$ phase, 1:1 transformation ratio. A seven phase resistive and inductive load connected in star is used for electrical loading of the transformer. The transformer primary winding is fed from a three single phase auto transformer to balance the input voltage. The transformer seven-phase output voltages are shown in Figure 14. The transformer is tested under balanced condition as well as under unbalanced condition. Experimental results are taken on Yokogawa four channel digital oscilloscope. Due to channel limitations, the wave forms are taken into two separate plots. Following steps are taken to get experimental data:

- A 100 KVA three phase to seven phase converting transformer is designed based on Section III and transformer design procedures.

- A prototype is made according to the design.

- The primary and secondary windings are left open. 
- The primary and secondary windings are connected later according to Figure 5.

- An RL load of $25 \Omega$ and $60 \mathrm{mH}$ is connected in Heptagon.

- The output waveforms are taken using YOKOGOWA 4channel digital oscilloscope.

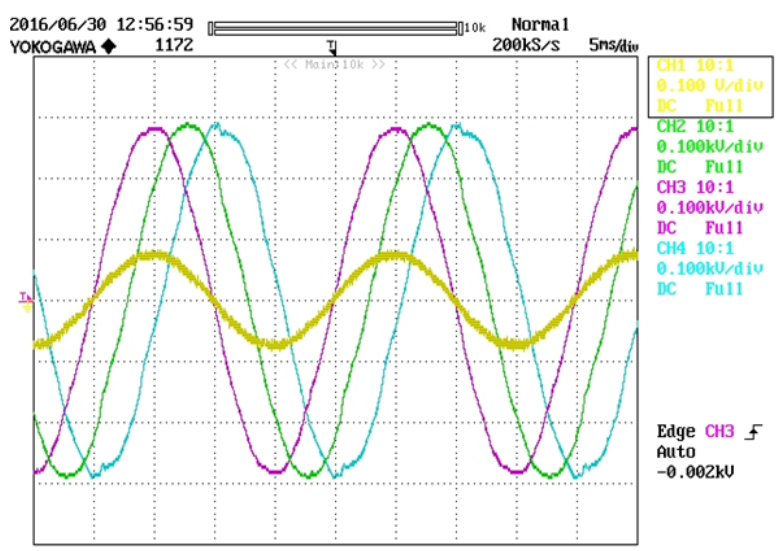

(a)

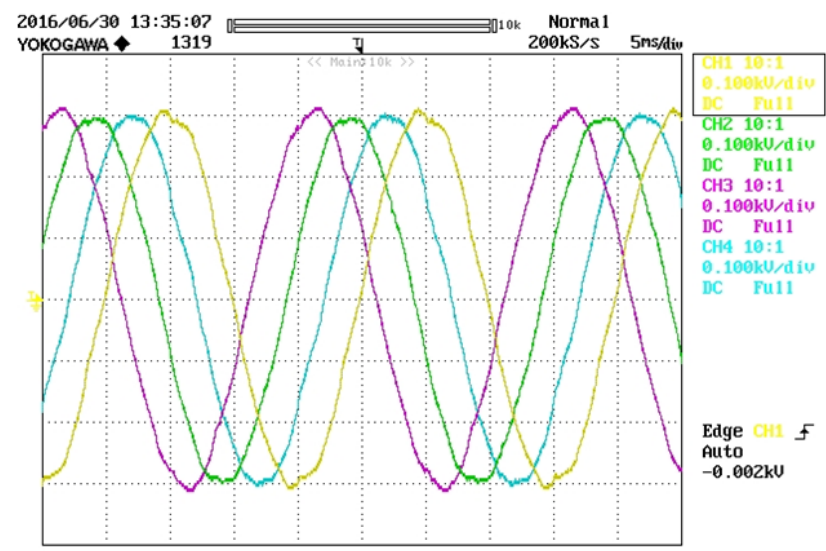

(b)

Fig. 14. Seven phase voltage waveform of experimental results

\section{DISCUSSION}

The designed transformer has many specific applications in different areas e.g.:

- Use in Power supply for multiphase induction motor or multiphase synchronous motor Drive for fixed speed operation.

- Use in testing of seven-phase machines

- Use as Power Transformer and Sub-transmission level Transformer for Multiphase Transmission

- Use in ac-dc converter. High ripple frequency lowers the filter rrequirement.

Since a transformer act as a two port network, a reverse transformation is also possible. In other words this transformer may be used as a tie between a seven phase generator and three phase grid. Furthermore a multiphase transformer can be explored in areas in addition to that mentioned in this paper

The presented connection scheme is compared with the scheme reported in [13]. The number of total windings in both schemes is almost the same. A considerable reduction in total volume is obtained in this scheme as the proposed transformer requires only two cores for winding together with a return magnetic path. So the overall volume of proposed transformer is less compared with that of [13] for the same rating. The actual amount of magnetic materials saved and the volume of transformer reduced is a design problem and could be addressed separately. Since all seven phases don't have the same number of windings so, impedance mismatching appears in both schemes. Consequently an unbalancing in voltage and current would appear. The unbalancing would be more prominent in case of full-load conditions. The proposed scheme reduces the impedance mismatching. As far as transformer losses are concerned, copper losses are the same but iron losses are reduced because magnetic material requirement is reduced in the proposed design. Since three phase input can't connect in star earthed so zero sequence current won't flow in case of fault or unbalanced conditions. A detailed comparison of both schemes (proposed and [13]) is show in Table VI.

TABLE VI. COMPARISON OF [13] AND THE PROPOSED SCHEME

\begin{tabular}{|c|c|c|}
\hline Difference in & Proposed Scheme & $\begin{array}{l}\text { Reported Scheme } \\
\text { in [13] }\end{array}$ \\
\hline Turns ratios & $\begin{array}{c}\text { Effective Total } \\
\text { windings }= \\
887.46 * 0.866=769\end{array}$ & $\begin{array}{l}\text { Total winding }= \\
770\end{array}$ \\
\hline Primary Windings & Scott-connection & $\begin{array}{r}\text { Star/Delta } \\
\text { Connection }\end{array}$ \\
\hline $\begin{array}{l}\text { Secondary } \\
\text { windings }\end{array}$ & Start or Heptagon & Star or Heptagon \\
\hline Number of Cores & 3 & 2 \\
\hline $\begin{array}{l}\text { Primary windings } \\
\text { Ratio }\end{array}$ & $1: 0.577: 0.577$ & $1: 1: 1$ \\
\hline $\begin{array}{c}\text { Secondary } \\
\text { windings Ratio }\end{array}$ & $\begin{array}{c}\text { 1:0.6234:0.7818:0.22 } \\
25: \\
0.9749: 0.9009: 0.4338: \\
0.9009: 0.4338: 0.2225: \\
0.9749: 0.6234: 0.7818\end{array}$ & $\begin{array}{c}0.1721: 1.00: 0.1721 \\
: \\
0.6505: 0.6505: 0.7854: \\
0.5010: 0.9028: 0.3404: \\
0.5010: 0.7854: 0.3404: \\
0.9028\end{array}$ \\
\hline $\begin{array}{c}\text { Effective } \\
\text { Res./Copper } \\
\text { Losses(per phase) }\end{array}$ & Low & High \\
\hline Iron Losses & Low & High \\
\hline $\begin{array}{c}\text { Secondary } \\
\text { winding Impedance } \\
\text { Ratios }\end{array}$ & $1: 1: 1: 1: 1: 1: 1$ & $\begin{array}{c}1: 0.844: 0.7327: \\
0.6741: 0.6741: \\
0.7327: 0.844\end{array}$ \\
\hline Volume & Lower & Higher \\
\hline
\end{tabular}

VI. CONCLUSIONS

In this paper a new transformer connection scheme which converts a three-phase power to a seven-phase output at constant frequency is presented. The connection scheme and the phasor diagram, along with the turns ratios, are illustrated. A general equation of phase transformation from three phase supply to $n$-phase supply using primary winding Scott connection based on vector/graphical approach is given. Based on that a connection scheme of three phase to seven phase 
transformer is presented. Proposed system is simulated in Simulink environment simulation. Results show that a balanced seven phase supply could be obtained from a balanced three phase input. The magnetic material requirement in this design is less especially for shell type of transformer as compared to existing approach due to two phase flux. Volume required for the same KVA rating will be less and power losses are less as well for the proposed scheme. Reduced losses obtained by the proposed system make it a more efficient system for phase converting transformer. The implementation of the proposed connection scheme is elaborated using simulation. Volume required for the same KVA rating comes out to be less. The proposed scheme has the reduced impedance mismatching up to a maximum value of $10 \%$ while reported connection scheme [13] has a significant degree of mismatching. Hence the proposed transformer is a more efficient and economically viable alternative of the reported three phase to seven phase converting transformer. It is expected that the proposed connection scheme can be used in drives and other multiphase applications like phase converting transformer. The implementation of the proposed connection scheme is elaborated using simulation. Volume required for the same KVA rating comes out to be less. The proposed scheme has the reduced impedance mismatching up to a maximum value of $10 \%$ while reported connection scheme [13] has a significant degree of mismatching. Hence the proposed transformer is a more efficient and economically viable alternative of the reported three phase to seven phase converting transformer. It is expected that the proposed connection scheme can be used in drives and other multiphase applications like transmission. Although the area of multiphase generation by passive transformation (using transformer) techniques is old, only limited research is done up to date compared to its counter-part: 3-,1- phase ac/dc/multiphase ac. Most research work available are focused on the phase number in the multiple of three, which opens up a wide window of research Therefore there are much more research options for odd number of phases like 5-phase, 7-phase, 11-phase etc. As far as 3-phase to 7-phase conversion is concerned, this paper could be extended for thermal modeling of the transformer. The unbalancing study, threeseven phase conversion and fault studies would be a breakthrough for this transformer study.

\section{APPENDIX}

\section{Impedance mismatching calculation}

From (7), one can show that the turns ratios of different windings placed on the two limb in matrix form are:

$$
\left[\begin{array}{ll}
1 & 0 \\
\cos (\delta) & \sin (\delta) \\
\cos (2 \delta) & \sin (2 \delta) \\
\cos (3 \delta) & \sin (3 \delta) \\
\cos (4 \delta) & \sin (4 \delta) \\
\cos (5 \delta) & \sin (5 \delta) \\
\cos (6 \delta) & \sin (6 \delta)
\end{array}\right]
$$

As explained in section III.A, the windings of two limbs are connected in series with proper polarity and turns ratios in $\sin (n \delta): \cos (n \delta)$ the value of $\delta=2 \pi / 7$ and $n=0,1,2,3,4,5,6$. Inductance of a coil is calculated by the following expression

$$
L=\frac{N^{2} \mu A}{l}
$$

where

$\mathrm{L}=$ Inductance of the coil

$\mathrm{N}=\mathrm{i}$-th number of turns

$\mu=$ Permeability of the core

$\mathrm{A}=$ Area of the coil

\section{$1=$ Average length of the coil}

Referring Figure 5: The inductance of each phase is sum of inductance of two individual coils. Each individual coil having turns ratios proportional to $\sin (\mathrm{n} \delta)$ and $\cos (\mathrm{n} \delta)$ where $\delta=\frac{2 \pi}{7}$ and $n$ varies from 0 to 6 .

$$
\begin{aligned}
& \text { So } \quad L \alpha \sin ^{2} n \delta+\cos ^{2} n \delta \\
& L \propto 1 \text { for } \mathrm{n}=0,1,2,3,4,5 \text { and } 6
\end{aligned}
$$

Therefore Inductance of each phase of secondary will be same.

\section{REFERENCES}

[1] E. Levi, "Multiphase electric machines for variable-speed applications", IEEE Transactions on Industrial Electronics, Vol. 55, No. 5, pp. 189319092008

[2] G. K. Singh, K. B. Yadav, R. P. Saini, "Modelling and analysis of multiphase (six-phase) self-excited induction generator", Proc. 8th Int. Conf. Electr. Mach. Syst., pp. 1922-1927, 2005

[3] G. K. Singh, K. B. Yadav, R. P Sani, "Capacitive self-excitation in sixphase induction generator for small hydro power-An experimental Investigation", Int. IEEE Conf. Power Electron., Drives Energy Syst., New Delhi, India, pp. 1-6, 2006

[4] J. R. Stewart, D. D. Wilson, "High phase order transmission- a feasibility analysis Part-II-Over voltages and insulation requirements", IEEE Trans. Power App. Syst., Vol. PAS-97, No. 6, pp. 2308-2317, 1978

[5] S. N. Tewari, G. K. Singh, A. B. Saroor, "Multiphase power transmission research-a survey", Electric Power Systems Research, Vol. 24, pp. 207-215, 1992

[6] M. Jones, E. Levi, "A literature survey of the state-of-the-art in multiphase ac drives”, Proc. Int. UPEC, Stafford, U.K., pp. 505-510, 2002

[7] E. Levi, R. Bojoi, F. Profumo, H. A. Toliyat, S. Williamson, "Multiphase induction motor drives-A technology status review", IET Electric Power Applications, Vol. 1, No. 4, pp. 489-516, 2007

[8] S. Choi, B. S. Lee, P. N. Enjeti, "New 24-pulse diode rectifier systems for utility interface of high power ac motor drives", IEEE Transactions on Industry Applications, Vol. 33, No. 2, pp. 531-541, 1997

[9] V. Garg, B. Singh, G. Bhuvaneswari, "A tapped star connected autotransformer based 24-Pulse AC-DC converter for power quality improvement in induction motor drives", International Journal of Emerging Electric Power Systems, Vol. 7, No. 4, 2006

[10] V. Garg, B. Singh, G. Bhuvaneswari, "A 24 pulse AC-DC converter employing a pulse doubling technique for vector controlled induction 
motor drives", IETE Journal of Research., Vol. 54, No. 4, pp. 314-322, 2008

[11] B. Singh, S. Gairola, "An autotransformer based 36 pulse controlled ACDC converter”, IETE Journal of Research, Vol. 54, No. 4, pp. 255-262, 2008

[12] A. Iqbal, S. Moinuddin, M. Rizwan Khan, S. M. Ahmed, H. Abu-Rub, "A novel three-phase to five-phase transformation using a special transformer connection", IEEE Transactions on Power Delivery Vol. 25, No. 3, pp. 1637-1644, 2010

[13] S. Moinoddin, A. Iqbal, H. Abu-Rub, M. Rizwan Khan, S. Moin Ahmed, "Three-Phase to Seven-Phase Power Converting Transformer", IEEE Transactions on Energy Conversion, Vol. 27, No. 3, pp. 757-766, 2012

[14] A. S. Abdel-Khalik, Z. Shafik, A. Elserougi, S. Ahmed, A. Massouda, "A static three-phase to five-phase transformer based on Scott connection", Electric Power Systems Research, Vol. 110, pp. 84-93, 2014

[15] J. E. Parton, "A general theory of phase transformation", Proceedings of the IEE - Part IV: Institution Monographs, Vol. 99, No. 2, pp. 12-23, 1952.

[16] O. E. Gouda, G. M. Amer, W. A. A. Salem, “A study of K-Factor Power Transformer Characteristics by Modelling Simulation”, Engineering, Technology \& Applied Science Research Vol. 1, No. 5, pp. 114-120, 2011

[17] H. Fan, J. Hu, H. Liu, Y. Yin, M. Danikas, "UHF PD Experiments on Real Power Transformer and its Frequency Characteristics Results", Engineering, Technology \& Applied Science Research Vol. 6, No. 1, pp. 906-912, 2016

\section{AUTHORS PROFILES}

Md. Tabrez received a Master and Bachelor degree in Electrical Engineering from Aligarh Muslim University in 2012 and 2010 respectively. Currently he is working as PhD Research Scholar in the Electrical Engineering Department of the Indian Institute of Technology, Dhanbad, India.

Pradip Kumar Sadhu received the B.E.E. (Hons.), M.E.E., and Ph.D. (Engg.) degrees from Jadavpur University, Kolkata, India, in 1997, 1999, and 2002, respectively. He is currently an Assistant Professor in the Electrical Engineering Department, Indian School of Mines, Dhanbad, India. His research interests include power electronics applications, energy efficient devices and drives, and computer-aided power system analysis

Atif Iqbal received the B.Sc. and M.Sc. degrees in electrical engineering from Aligarh Muslim University (AMU), Aligarh, India, in 1991 and 1996, respectively, and the Ph.D. degree from Liverpool John Moore University, Liverpool, U.K., in 2006. He has been a Lecturer in the Department of Electrical Engineering, AMU, since 1991, where he is currently working as an Associate. He is on an academic assignment at Qatar University, Doha, Qatar. His main research interests are power electronics and multiphase machine drives. 